PROARTSS REPORT NO. 2

$$
\text { to the }
$$

DIVISION OF RESEARCH

o. S. ATOMIC FNHROY COMAISSION

on

Contract No. AT $(11-1)-1629$

THIBRMAL MEASURTYYDNTS ON BOLIDS

BBIOW $1^{\circ} \mathrm{K}$

by

Harold WeInstock

Associate Professor of Phystce

January, 1968

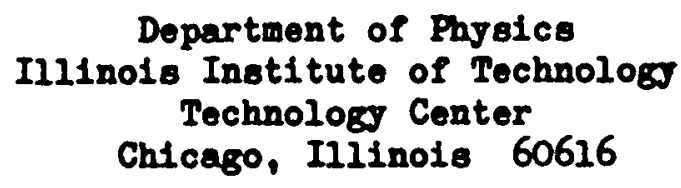




\section{DISCLAIMER}

This report was prepared as an account of work sponsored by an agency of the United States Government. Neither the United States Government nor any agency Thereof, nor any of their employees, makes any warranty, express or implied, or assumes any legal liability or responsibility for the accuracy, completeness, or usefulness of any information, apparatus, product, or process disclosed, or represents that its use would not infringe privately owned rights. Reference herein to any specific commercial product, process, or service by trade name, trademark, manufacturer, or otherwise does not necessarily constitute or imply its endorsement, recommendation, or favoring by the United States Government or any agency thereof. The views and opinions of authors expressed herein do not necessarily state or reflect those of the United States Government or any agency thereof. 


\section{DISCLAIMER}

Portions of this document may be illegible in electronic image products. Images are produced from the best available original document. 


\title{
Progress Report No. 2
}

on

Thermal Measurements on Solids Belou $1^{\circ \mathrm{K}}$

\author{
submitted by \\ Harold veinstock \\ Department of Phyśics \\ Illinois Institute of Technology \\ INTRODOCTION
}

This report smmarizes the work done on this project from January, 1967 to the present principally on the eriect of locairized impurities and magnetic order on the thermal conduction and heat capacity of insulating and retallic solids. The participating stafe consisted of H. Veinstock (Associate Professor of Physics), A. Harris. (Assistant Professor of Physics), R. A. Guenther (Instructor); the Pollowing graduate students: Ro F。 Koch, C. Ni, and Ro Vo Carlson; and undergraduate students: Ro Schleicher, Jo Vandendorpe, and J. A. Morel.

A brief sumary of the current status of each project follows: 1. Investigation of Localized Mode and Colloid Scattering in Alkali Halides

A series of measurements of thermal conductivity in the range of $0.4^{\circ} \mathrm{K}-4.0^{\circ} \mathrm{K}$ have been carried out on initially high purity $\mathrm{KCl}$ single crystals. Prior to measurement, each crystal was subjected to varying dosages of gamma irradiation at both room temperature and 1iquid nitrogen temperature. In one run, irradiation at liquid nitrogen

\section{LEGAL NOTICE}

This report was prepared as an account of Government sponsored work. Neither States, nor the Commission, nor any person acting on belalf impled with respect to the accuA. Makes any warranty or representation, expressed or implled, wh report, or that the use racy, completeness, or usefulness of the Information contalned in this report may not infringe of any information, apparatus, method, or process disciosed in thlo report may nos infringe privately owned rights; or

B. Assumes any liabilities with respect to the use of, or for damages resulting from the se of any information, apparatus, method, or process disclosed in thls report. As used in the above, "person acting on behall of of such contractor, to the extent that ployee or contractor of the Commisston, or employee of such con such contractor prepares, such employee or contractor of the Com information pursuant to his employment or contract disseminates, or provides access lo, ane with such contractor. 
temperature was followed by direct cooling to liquid helium temperatures, ive, without warming to room temperature before reasuring the conductivity of the irradiated crystal. The results of these measurements indicate a "resonant" type decrease in the conductivity below 1 oK in specimens winich have undergone high room temperature doses $\left(\sim 10^{8}-10^{9} r\right)$ and posseas correspondingly high $\left(\sim 10^{18} / \mathrm{cm}^{3}\right)$ F-center concentrations. This behavior can be interpreted in terms of a geometrical scattering resonance consistent with the model of halide colloids proposed by Sonder et al ${ }^{l}$. The measurements themselves are consistent vith chose of Sonder and Ualton ${ }^{2}$ also done on KCI and those or Uleinstock ${ }^{3}$ on Iir. An additional result or some significance is the fact thet the crystal: irradiated at liquid nitrogen temperature and measured immediately showed a relatively low conductivity which increased considerably after cycling to room temperature. This too is consistert with work reported by Pohl ${ }^{4}$ on LiF at higher temperatures. It leads to the conclusion that there is a recombination or annealing of latice defects (produced at $77^{\circ} \mathrm{K}$ ) which occurs between $77^{\circ} \mathrm{K}$ and $300^{\circ} \mathrm{K}$. C 2. Conduction Characterisicics of Magnetically Ordered Solidis

A cryostat designed to measure thermal conductivity in a high (superconducting) magnetic field dom to $0.3^{\circ} \mathrm{K}$ has been constructed ard has. successfully undergone preliminary testing。 It reatures a crystal holder which allows the crystal to be rotated $360^{\circ}$ with respect to the magnetic field axis. In addition, electrical leads to the magnet may be removed entirely when the magnet is operating in its persistent mode; 
thus heat leak to the cryostat is greatly reduced.

Considerable progress has also been made on the growing of paramagnetic salts from aqueous solution by maintaining a metastable state at constant temperature, concentration and humidity. Single crystals, easily sizable enough for thermal conductivity studies, have seen produced in $\mathrm{MnCl} \cdot 4 \mathrm{H}_{2} \mathrm{O}$ and $\mathrm{COCl}_{2} \cdot\left[\left(\mathrm{NH}_{2}\right)_{2} \mathrm{CS}_{4} \cdot\right.$ Crystals which are marginally large enough for such studies have been produced in $\mathrm{AnCl}_{2} \cdot\left[\left(\mathrm{NH}_{2}\right)_{2} \mathrm{CS}\right]_{4}$ and $\mathrm{CoCl}_{2} \cdot 6 \mathrm{H}_{2} \mathrm{O}$.

3. Specific Heat of Insulators and Alloys

A cryostat for the measurement of specific heat in the region from $0.3^{\circ} \mathrm{K}$ to $25^{\circ} \mathrm{K}$ has been constructed and is being checked out. Work is also nearing completion on a crystal growing facility for the production of pure or alloyed metallic specimens, either in single crystal or polycrystalline form; and with suitable dimensionality for thermal conductivity as well as specific heat measurement. This. is being accomplished by incorporating a high vacuum system with a three inch bore Lindberg tubular oven capable of controlled temperatures to $1100^{\circ} \mathrm{C}$. 
1. Investigation of Localized Mode and Colloid Scattering in Alkali Halides Using both Harshaw commercial high purity KCl single crystals and one (KCl single crystal) of much higher purity grown at Oak Ridge National Laboratory by C. T. Butler et al ${ }^{5}$. low temperature thermal conductivity measurements were carried out subsequent to various radiation and temperature treatments. This was done in an attempt to determine the mechanism responsible for thermal resistance below $I^{\circ} \mathrm{K}$ and to relate this to a model of lattice defects produced by ionizing radiation.

In earlier work by Pohl ${ }^{4}$ and Walker ${ }^{6}$ above $1^{\circ} \mathrm{K}$, it was shown that the observed conductivity and its temperature dependence in irradiated and additively colored alkali halides can be explained in terms of scattering by F-centers. However, this scattering mechanism below about $2^{\circ} \mathrm{K}$ was found to be quite weak. Recently, Sonder et al ${ }^{l}$ have suggested that indirect evidence, based on flow stress and ultraviolet absorption measurements, leads to a model in which interstitial clusters of anion (halide) interstitials are produced by the ionizing gamma radiation. Furthermore, they suggest that the size of the clusters depends upon the ambient specimen temperature during irradiation.

Experimental measurements on the conductivity of $\mathrm{NaCl}$ single crystals containing various sized colloids by Worlock ${ }^{7}$ and Walton ${ }^{8}$, and a theoretical treatment of phonon scattering by spherical colloids by Walton and Lee ${ }^{9}$, together have shown that the size of a scattering 
sphere $(\sim 100 \AA)$ can be deduced from the temperature dependence of the conductivity at sufficiently low temperatures -- generally, less than $1 \% \mathrm{~K}$. It is with this background in mind that the presently reported measurements were carried out and will an analyzed.

Figure I shows three curves of thermal conductivity vs. temperature for

A. A pure unirradiated Harshaw KCl crystal.

B. The same crystal as in A after $\mathrm{Co}^{60} \gamma$-irradiation at $77^{\circ} \mathrm{K}$ for 93 hours with $1.6 \times 10^{5} \mathrm{r} / \mathrm{hr}$ to give a total dosage of $1.5 \times 10^{6}$ rads. The conductivity measurements were made without warm-up.

C. The same crystal as in A and B after warming to room temperature, and remaining there for four days before re-cooling. The F-center concentration after subsequent warm-up was found to be $3.1 \times 10^{16} / \mathrm{cm}^{3}$.

Each curve is represented as a solid line for clarity only and represents an averaging of from 60 to 80 points in the temperature range covered. Average deviation of a point from the curves shown is less than $2 \%$. [ypical (but not all) data points are shown for the curves in Figure 4 ]

The qualitative features of Figure 1 are quite similar to those obtained by Pohl ${ }^{4}$ for $X$-irradiated $\mathrm{LiF}$ at $77^{\circ} \mathrm{K}$. Using an argument based on observations 10,11 that colloids redissolve well above room temperature, he concluded that the defects produced by low temperature irradiation cannot be colloids and are probably of atomic dimensions. However, colloids produced by X-rays or ganma rays are. not Iikely to be a collection of alkali atoms as is produced by additive coloration. 
1.6.

.9.

$.3{ }^{4}$

$.7 \cdots$

.3

.5

$\therefore$

$\therefore$

$\therefore$

0

$\therefore$

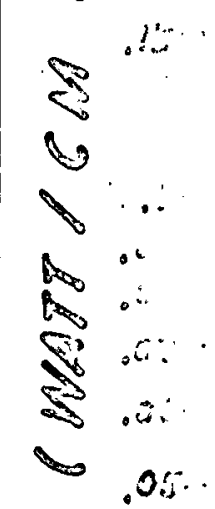

$\sum_{0} .0 \%$

$\infty .03$

$\infty .02$

(1)

.02.

2

015.

1

1. .01 $.00 \%$ .009 $.007 \%$ $.006 !$ .00.

0

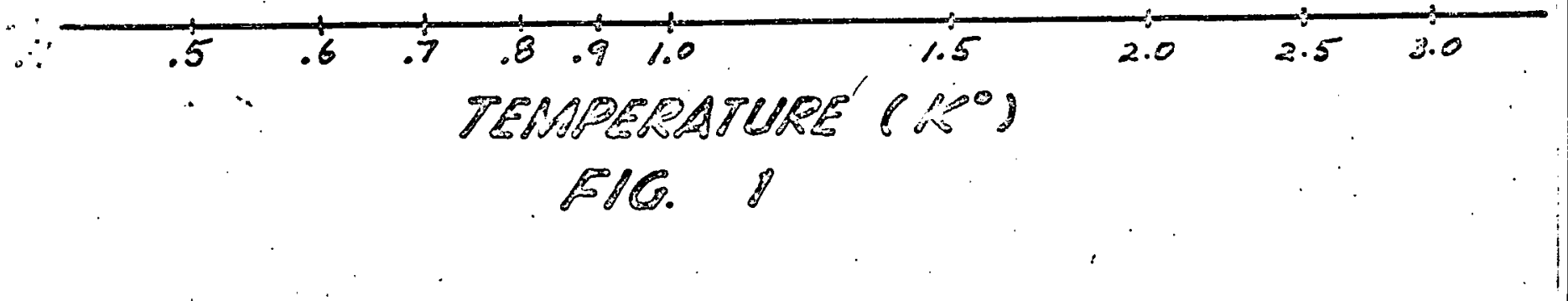


Since the observations ${ }^{10,} 11$ on colloid dissolution are for additively colored crystals, and since subsequent analysis 6,7 of thermal conductivity data has showed that scattering due to point defects of atomic dimensions would be absent at such low temperatures, it can is concluded from these current measurements that defects other than those suggested by Pohl are present due to low temperature $\left(77^{\circ} \mathrm{K}\right)$ irradiation. Figure 2 shows three curves of thermal conductivity vs. temperature for A. A pure unirradiated Harshaw KCl crystal.

D. A Harshaw crystal after $C_{0}^{60} \gamma$-irradiation at room temperature for 88 hours with $1.6 \times 10^{5} \mathrm{r} / \mathrm{hr}$ to give a total dosage of $1.4 \times 10^{8}$ rads. The F-center concentration produced was $2.4 \times 10^{17} / \mathrm{cm}^{3}$

E. A Harshaw crystal after $\mathrm{Co}^{60} \gamma$-irradiation at room temperature for 278 hours with $3.4 \times 10^{6} \mathrm{r} / \mathrm{hr}$ to give a total dosage of $9.4 \times 10^{8}$ rads. The F-center concentration produced was $8.9 \times 10^{17} / \mathrm{cm}^{3}$.

The $D$ and $E$ curves are in agreement with measurements above $1.2^{\circ} \mathrm{K}$ done on similarly irradiated $\mathrm{KCl}$ by Walker ${ }^{6}$. A rather interesting new type of behavior is seen, however, in the conductivity at temperatures below $1^{\circ} \mathrm{K}$. In this region there is evidence of a resonant type of decrease in conductivity, only slightly evident in the $D$ curve, but more pronounced in the $\mathrm{E}$ (or more heavily irradiated) curve.

Before discussing the significance of the Figure 2 results, we present Figure 3. This shows curves $A$ and $E$ again along with curve $F$ for another Harshaw KCI crystal which had received a total $\gamma$-irradiation. 


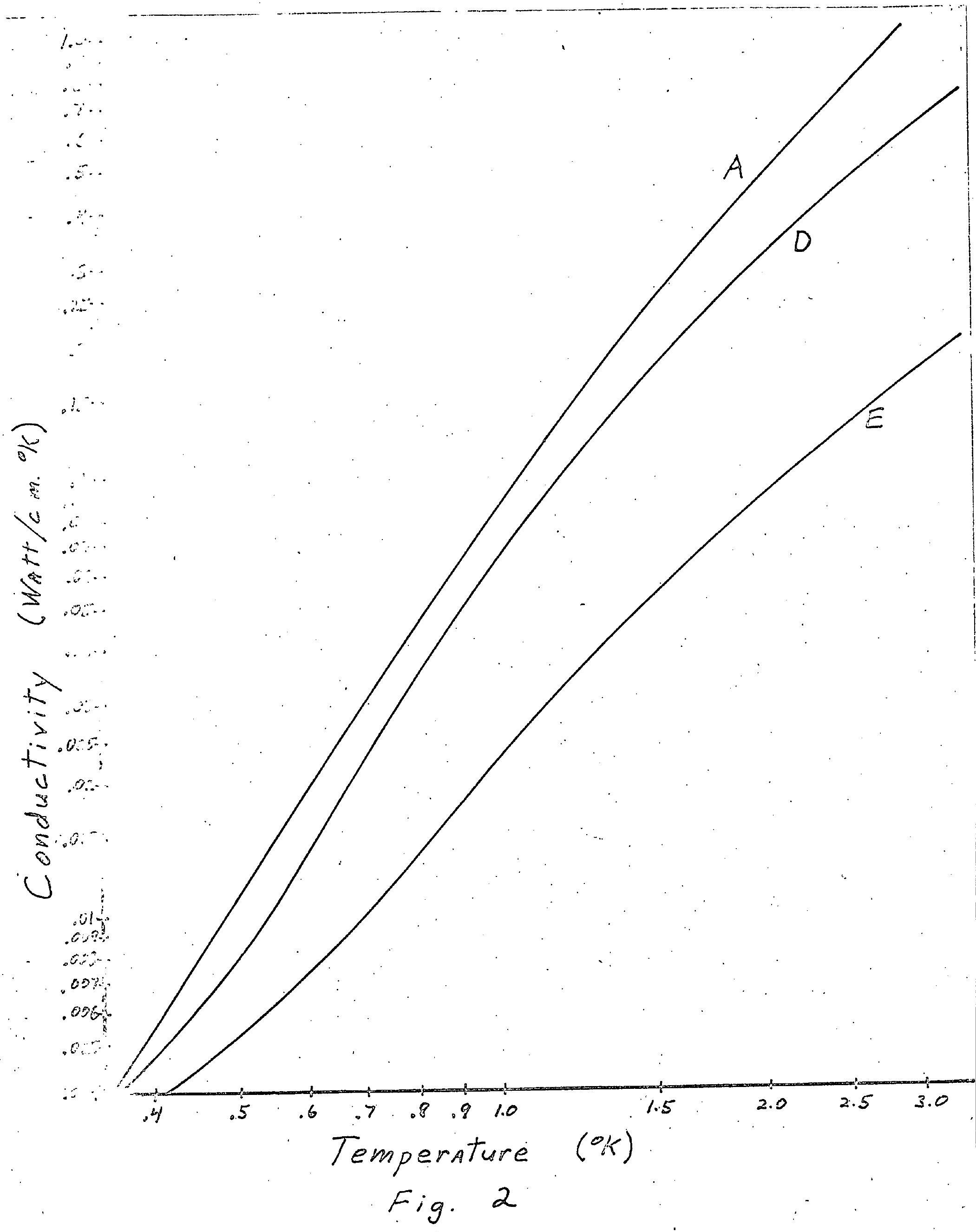




$$
1
$$


of $3.7 \times 10^{8}$ rads at $77^{\circ} \mathrm{K}$ and was warmed to room temperature for about three days before measurements were taken. The combined information of Figures 2 and 3 indicate that the resonant type scattering of phonons is due not to a localized mode resonance of the type measured by several investigators in recent years. ${ }^{12-15}$. Rather, it is believed that a "geometrical" type resonance is observed, i.e., a maximum in the thermal resistivity is seen for a temperature range in which the wavelength of dominant phonons matches the linear dimensions of the scattering defects. The fact that the resonant temperature region appears to shift according to temperature of irradiation is explainable by the fact that at the higher (room) temperature irradiation larger aggregates may be formed. The larger aggregates then scatter more effectively at lower temperatures as observed. These results are in accord with somewhat more limited $\mathrm{KCl}$ conductivity measurements by Sonder and Walton. 2 In addition, all these results fit in well with the proposed model of Sonder, et al $^{l}$ on the formation of halide colloids in -irradiated alkali halides.

Figure 4 shows some of the data points for curve $E$ in Figure 2, along with some of the points obtained for a $\mathrm{KCl}$ crystal of the same approximate cross-section, $1 / 8 " \times 1 / 8 "$, and irradiated identically, but of a much higher purity. The purity of this (curve G) crystal is well documented ${ }^{5}$ and was supplied through the courtesy of Dr. E. Sonder of Oak Ridge National Laboratory. "It is seen that the curvature of 


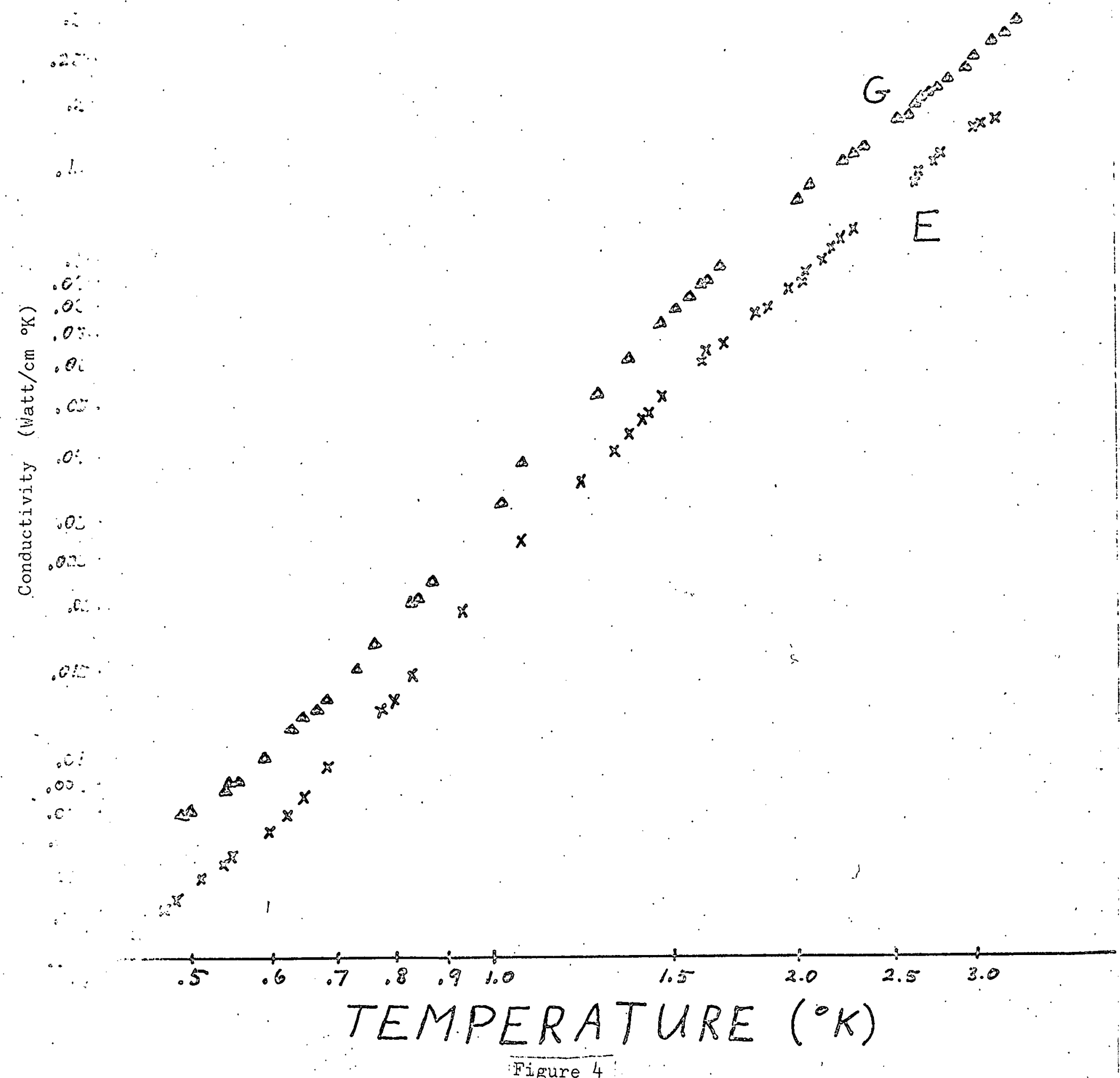

Figure 4 
the two curves is (within experimental precision) identical over the entire temperature range covered. Thus, it may be stated reliably that the formation of halide colloidal particles, as proposed by Sonder, is not inhibited by impurities present in the Harshaw crystal (and missing in the Oak Ridge crystal). These impurities may manifest themselves in the lower overail conductivity, but in no way mask the scattering of the colloids produced by the irradiation of $\gamma$-rays.

A complete analysis of all the curves presented in this report is being carried out by computer to determine the effective size of scatterer on the basis of various scattering cross-section vs. frequency dependences. This is being done somewhat in the fashion of the analysis of Walton ${ }^{8}$ for silver colloids in sodium chloride. However, various approximations to the cross-section dependence are being made in order to test the sensitivity of the data to these, and to test the variation in predicted size of scatterer which may result.

One side result of the work reported above concerns itself with the reproducibility of calibration curves for commercial carbon composition resistance thermometers. For many years these have been used as inexpensive, but generally considered non-reproducible, thermometers. Also, because this early work ${ }^{16}$ was carried out on Allen-Bradley brand resistors, subsequent investigators went to great lengths to use only that brand although it was not always easy to come by. The present investigations have used Ohmite brand carbon composition resistors exclusively, with results paralleling those for the Allen-Bradley ones. A call to the Obmite Corporation has, indeed, confirmed the fact that 


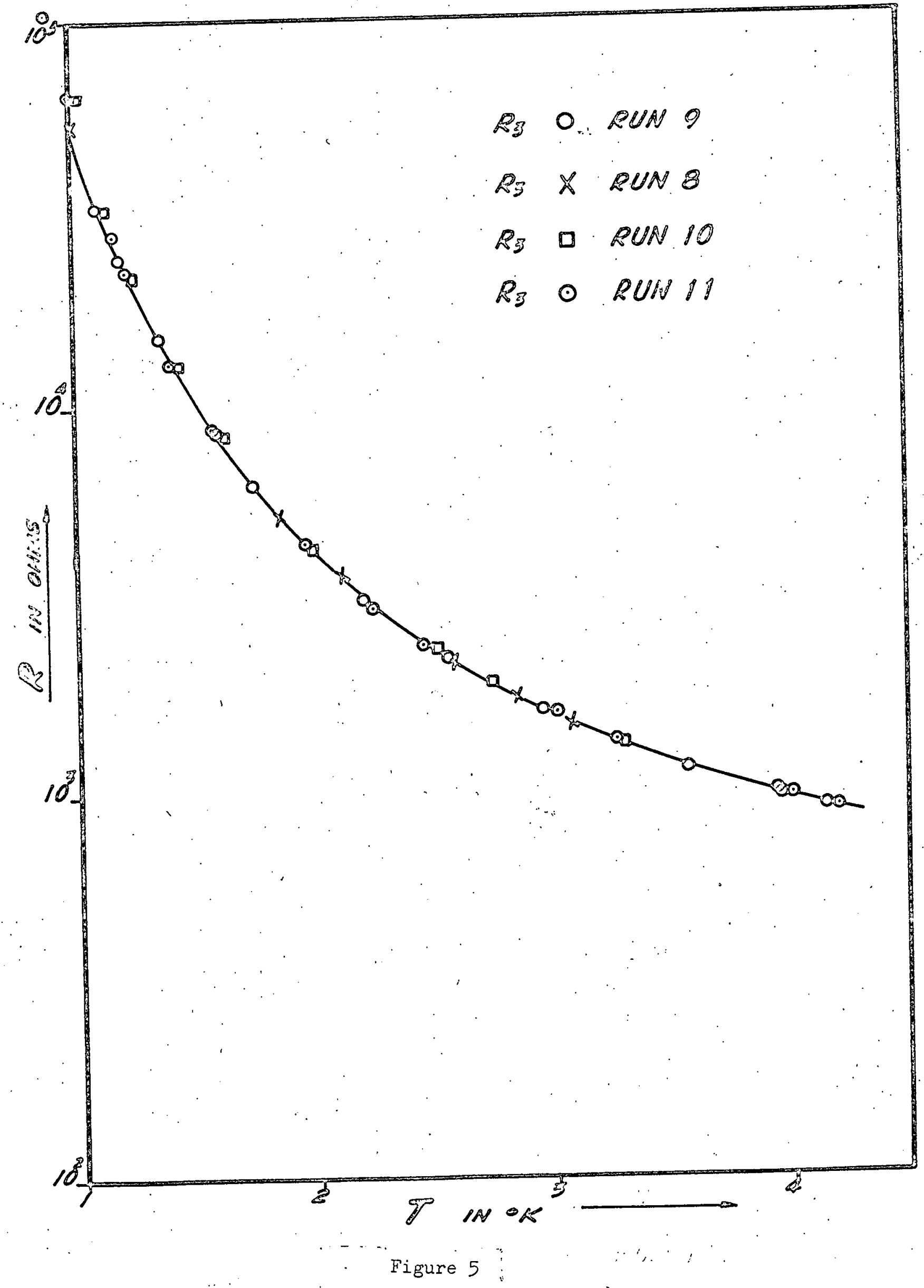


their carbon composition resistors are manufactured by Allen-Bradley, but are marketed by them (Ohnite) on a much wider basis.

Of much greater significance is the fact that these resistors have greater reproducibility with respect to temperature than previously reported. Figure 5 shows a calibration curve for a nominal 68 ohm. 1/8 watt, $10 \%$ Ohmite resistor obtained over the period of one month with cycling to room temperature between each of the four low temperature runs. All calibration points fall on the same curve to a precision of about 1\%. With somewhat higher precision, small deviations from the original curve can be detected. Five subsequent runs over an additional. four month period have failed to reveal significant, i.e., greater than 1\%, deviations from this curve. Another interesting result of these calibrations, is that the second calibration ( $r$ n 9) was carried out after the resistor had been subjected to a $\gamma$-irradiation (emanating from a $\mathrm{Co}^{60}$ source) of $1.5 \times 10^{6}$ rads at $77^{\circ} \mathrm{K}$. 'Apparently, the effect on the temperature calibration curve of this is negligible. This fact may prove to be quite important since other types of common cryogenic thermometers, are known to be extremely sensitive to radiation and are unreliable in a radioactive environment. The only requirement for reproducibility of carbon composition resistance thermometers is that they be soldered into position each time they are used without allowing the body of the resistor to heat much above room temperature. This can be accomplished easily by use of a heat sink. This same precaution 
must also be followed in the case of germanium thermometers, which in general are not as rugged as the carbon thermometers.

Preliminary results of the thermal conductivity data bave been reported 17 at the June, 1967 Meeting of the American Physical Society. Subsequent data and analysis is being prepared for presentation at the April, 1968 Meeting of the Society, and the entire thermal conductivity work in this area will be submitted to the Physical Review. It will also form the basis for the $\mathrm{Ph}$. $\mathrm{D}$. thesis of $\mathrm{R}$. A. Guenther. The information on carbon resistance thermometry is being prepared for submission as a note to Cryogenic Technology, and, in part, will form the basis for the M. S. thesis of R. F. Koch. 2. Conduction Characteristics of Magnetically Ordered Solids

A report on measurements of the thermal conductivity of single crystals of $\mathrm{CoCl}_{2} ;\left[\left(\mathrm{NH}_{2}\right)_{2} \mathrm{CS}\right]_{4}$ at temperatures both above and below. the Néel temperature has been made. ${ }^{18}$ Although this work had been reported earlier ${ }^{19}$, it had only a limited audience. In addition, the appearance of an enhancement in thermal conductivity along the direction of lattice submagnetization below the Neel temperature has been interpreted in light of comments by Huber. 20 It is Huber's contention that critical fluctuations in the neighborhood of a magnetic phase transition may cause an anomalous increase in thermal conductivity in this temperature region. While the measurements presented by the principal investigator -- see Figure 6 - may possibly present evidence 


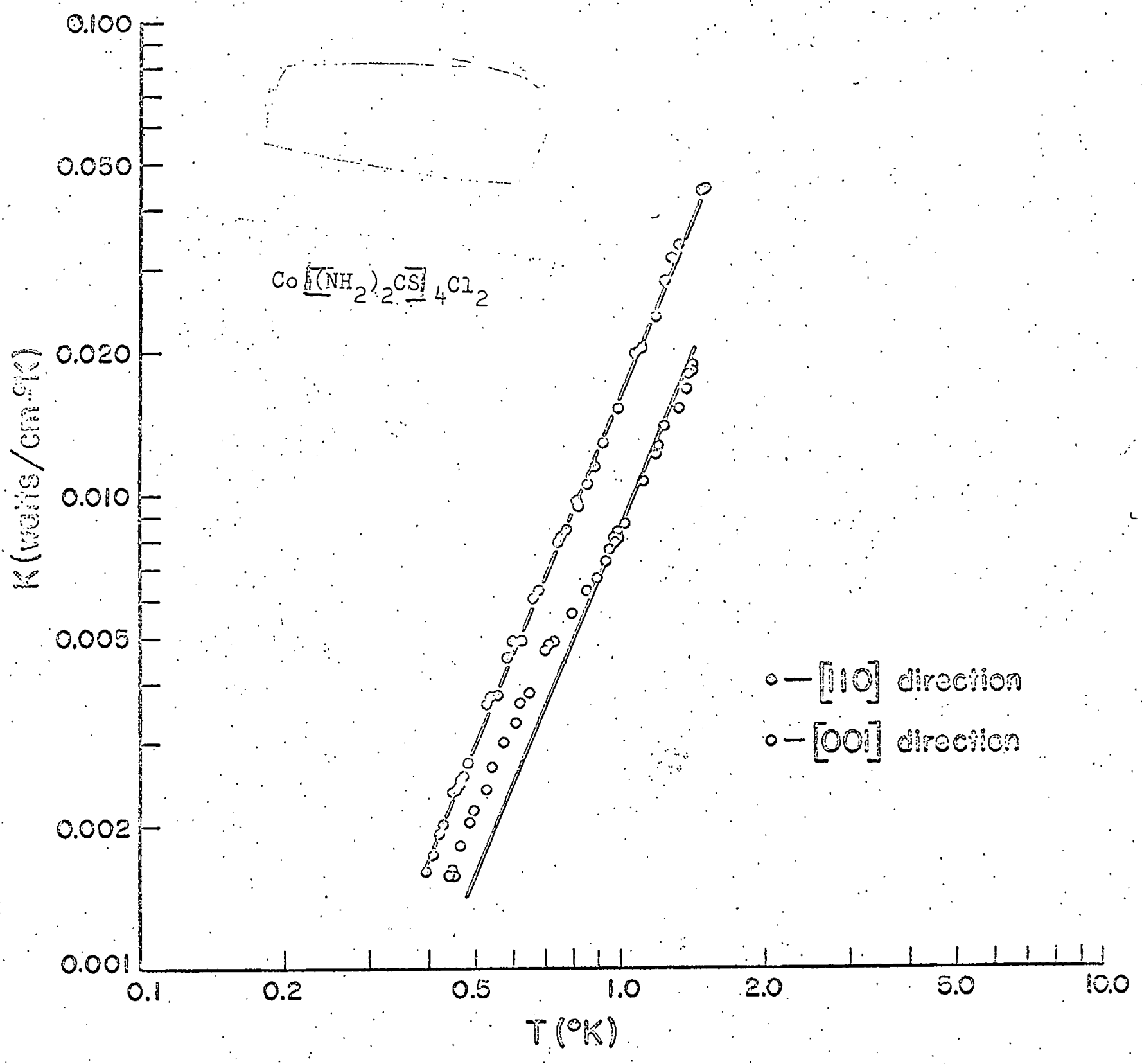

Figure 6 . 
of this, it was pointed out by same that other interpretations are possible. Additionally, it was recalled that for $\mathrm{MnF}_{2}$, only a slight decrease in conductivity was observed 21 at the Néel temperature. Definitive work on the effect of magnetic ordering on thermal conductivity can be carried out only in a system for which a high magnetic field may be applied (and removed) in various specified crystallographic directions. A cryostat for just such measurements has been constructed and, after preliminary testing, appears ready to be employed in this investigation. The magnetic field is supplied by a two inch bore, four inch active length superconducting magnet, capable of operating in a persistent mode up to a field of over 30 kilogauss. The crystal holder is designed to provide complete rotational freedom. of the crystal in the two directions perpendicular to the magnetic field axis. Details of the cryostat design and the crystal holder construction are, illustrated in Figure 7.

\section{Figure 7 Legend}

Cryostat

i. Rotationally Adjustable Crystal Clamp

2. Crystal Holder

3. Superconducting Magnet

4. $\mathrm{He}^{3}$ Refrigerator

5. Inner Can

6. Outer Can

7. Magnet Supporting. Flange and Radiation Shield 


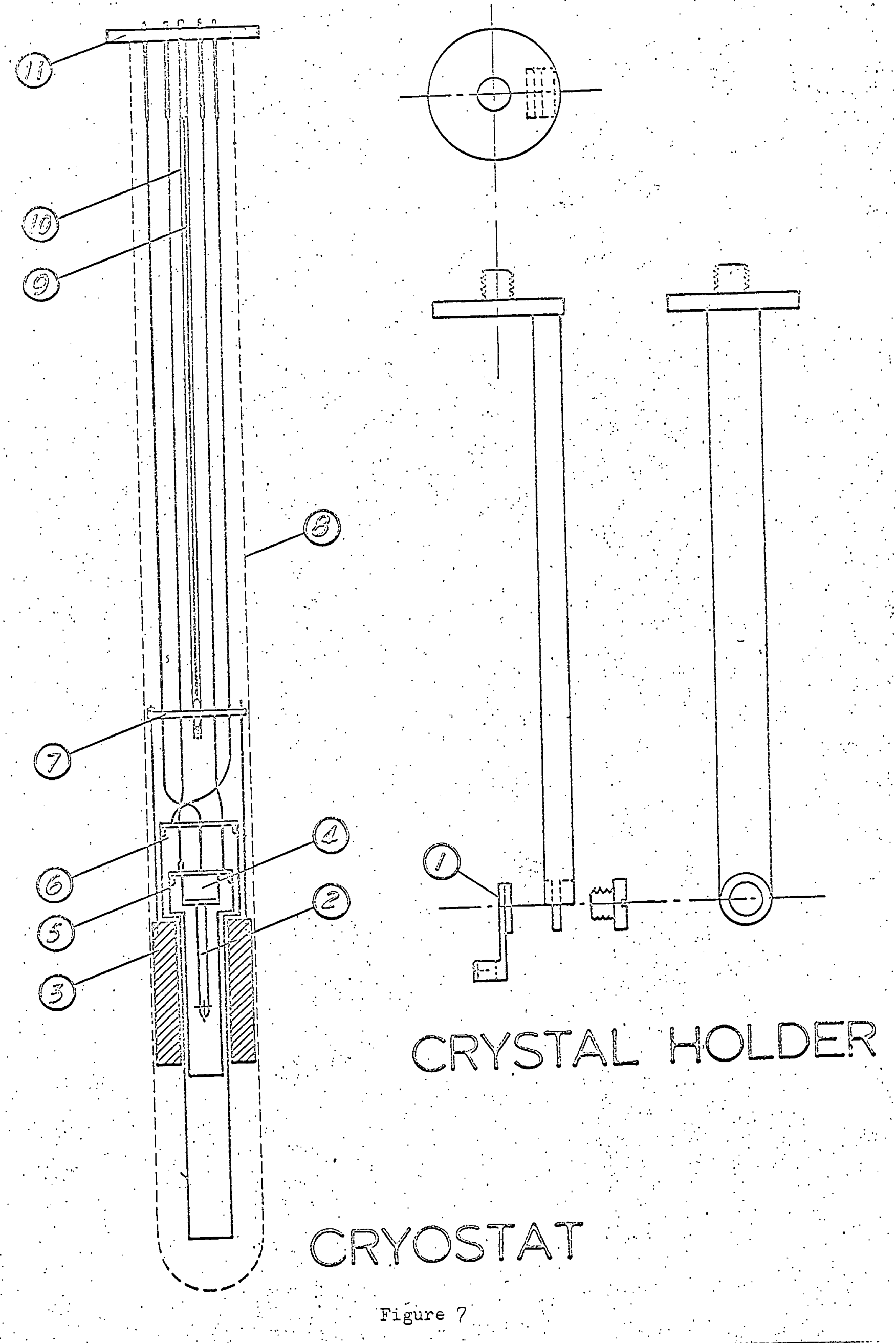


8. Dewar.

9. Removable Electrical Plug

10. Electrical Plug Support

11. Top Flange

The second major effort in this phase of the program has been in the area of crystal growth from aqueous solution. The difficulty is not so much to grow the desired single crystals, but to grow them large enough and periect enough for suitable thermal conductivity. measurements. In the evaporation method used, trouble arises in the form of cracks and of seed crystals (formed at the surface of the solution) depositing out on the crystals being grown. This last effect results from the fact that evaporation causes the solution to be denser near the surface. A system has now been set up to reduce these problems.

The solution' is circulated within a reasonably closed system. Within the crystal growing vessel the solution is maintained in a metastable state at constant temperature and concentration. The constant concentration is achieved through the use of a saturated solution at a higher temperature. This saturated solution is siphoned into a temperature-humidity control chamber at a controlled rate, and flows through a long length of tubing within the control chamber in order to achieve the ambient temperature before entering the crystal growing vessel. A well is provided in the vessel to trap aggregates (should they exist) and to eliminate non-uniform flow about the growing crystals. 
The solution level is kept constant by means of a pump-out rell backed by a Ministaltic Chemical Pump which directs the flow back into the source container. Excess chemicals are added to this container to malntaln the saturated solution at the set temperature. Fow through the crystal growing vessel aids in moving seed crystals, if any, away from the region where the crystals are being grown. A more uniform environment for these crystals is obtained still further by rotating them slowly at a rate of five revolutions per minute. A schematic of this entire set-up is shown in Figure 8.

\section{Figure 8 Legend}

\section{Crystal Growing Apparatus}

1. Temperature and Humidity Control Chamber

2. Crystal Growing Tank

3. Trap Well

4. Main Tank

5. Pump-out Well

6. Crystal

7. Cooling Tube

8. Pulley System

9. Motor

10. Fow Rate Adjuster

11. Pump

12. Saturated Chemical Solution (At bath temperature)

13. Excess Chemicals 

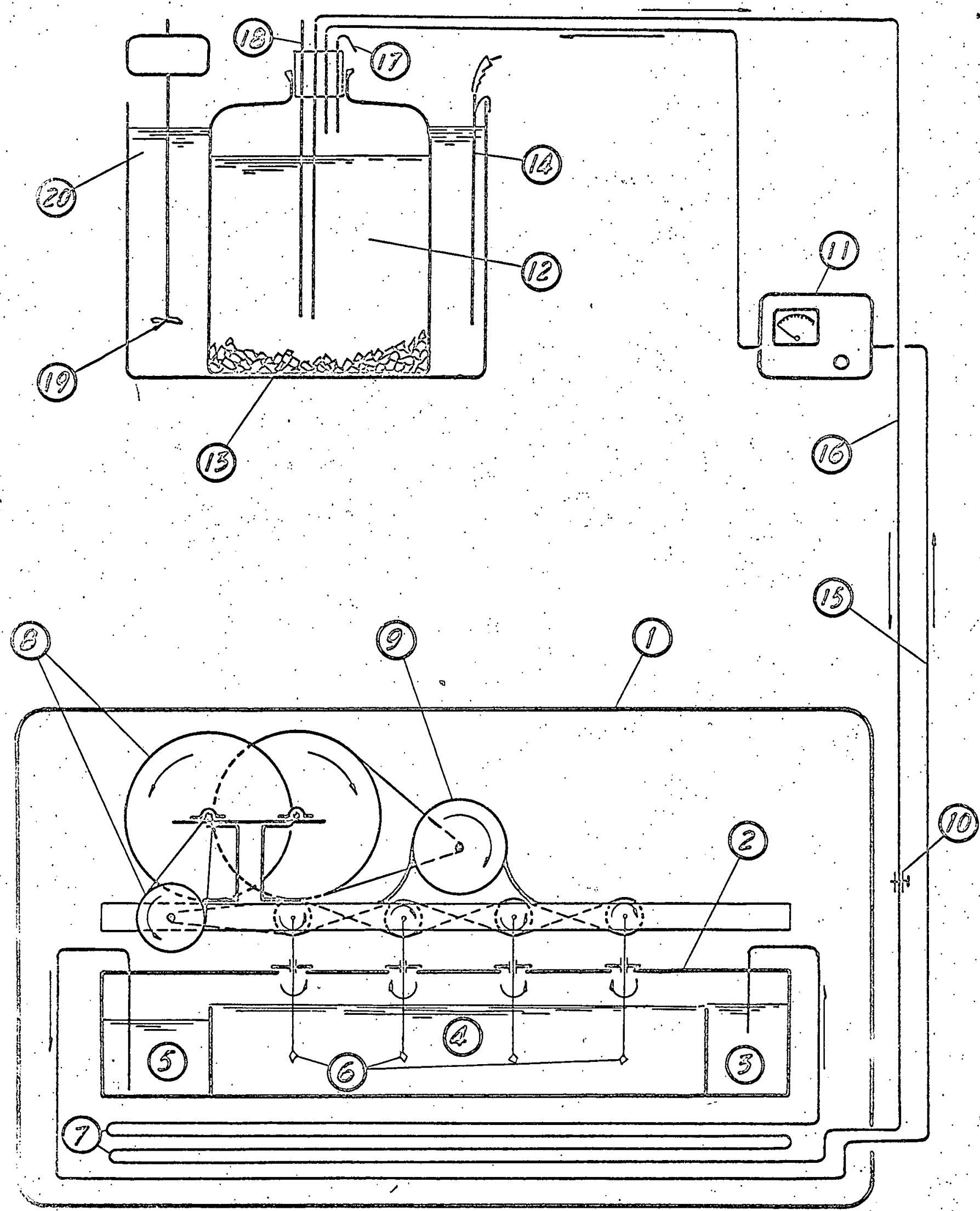

CRYSTAL GROWING APPARATUS Figure 8 
14. Heater

15. Pumping Line

16. Feeding Iine

17. Vent Tube

18. Thermometer

19. Stirrer

20. Temperature Bath

The apparatus described has been used successfully to grow crystals of $\mathrm{CoCl}_{2}\left[\left(\mathrm{NH}_{2}\right)_{2} \mathrm{CS}_{4}\right.$ and $\mathrm{MnCl}_{2}: 4 \mathrm{H}_{2} \mathrm{O}$ suitable for thermal conductivity. studies. Single crystals of $\mathrm{MnCl}_{2} \cdot\left[\left(\mathrm{NH}_{2}\right)_{2} \mathrm{CS}\right]_{4}$ and $\mathrm{CoCl}_{2} \cdot 6 \mathrm{H}_{2} \mathrm{O}$ have also been grown, although their size and quality are so far of only marginal value. $\mathrm{NiBr}_{2} \cdot \mathrm{X} \mathrm{H}_{2} \mathrm{O}$ crystals of small size have also been grown under refrigerated conditions, but melt when brought to room temperature. Efforts are being made to improve the size and quality of the single crystals produced. These involve the use of higher purity chemicals, more effective removal of unwanted seed crystals, and more uniform crystal rotation.

Alioys which undergo transitions due to magnetic ordering are also being considered under this part of the program. Progress in the growth of such specimens is reported in the following section. 


\section{Specific Reat of Insulators and Alloys}

Low temperature specific heat measurements to investigate local mode excitation, phonon-electron interactions, and magnetic phase transitionshave been planned. To this end, a cryostat for the measurement of specific beat in the region from $0.3^{\circ} \mathrm{K}$ to $25^{\circ} \mathrm{K}$ has been constructed and is currently under test. The cryostat can be adapted for measurements of differential heat capacity ${ }^{22}$, i.e., the difference in heat capacity (at any temperature) between two specimens, usually of like mass and only slightly different composition or state.

In connection with both this work and that on the thermal conductivity of magnetically ordered specimens, a need has arisen for a system to grow alloy specimens. As a result, a facility is being established to grow shaped metallic specimens -- pure or alloyed -- in single crystal or polycrystalline form, as desired. A three inch bore Iindberg tubular oven capable of maintaining controlled temperatures to $1100^{\circ} \mathrm{C}$ is being installed. Specimens are to be made in a tube -- part of a high vacuum system -- passing through the oven by means of a geared drive mechanism. The oven, controller and vacuum components are being self-contained as a single (large) bench unit.

New Equipment Supplied to Laboratory by IIT

In addition to laboratory equipment supplied by IIT to establish its Low Temperature Laboratory (as indicated in the original proposal for 
support); and in addition to the equipment supplied or on order at the time of submission of Progress Report No. I; the following equipment has been added or is now on order:

Hewlett-Packard Universal Impedance Bridge

S. S. White Abrasive Cutting Unit

Leeds and Northrup Kelvin Bridge. (4287)

General Radio Precision. Frequency Counter and Timer

(1191) 
Bibliography

1. E. Sonder, W. A. Sibley, J. E. Rowe and C. M. Nelson, Phys. Rev. I53, 1000 (1967)

2. E. Sonder and D: Walton, Phys. Lotters 25A, 222 (1967)

3. H. Weinstock, A. Friend and I. Khadduri, Bull. Am. Fhys. Soc. 10, 1095 (1965)

4. R. 0. Pohl, Phys. Rev. 118, 1499 (1960)

5. C. T. Butler, J. R. Russell, R。 B。 Quincy, Jr. and D. E. LaValle, J. Chem. Phys. 45, 968 (1966)

6. C. T. Walker, Phys. Rev. 132, 1963 (1963)

7. J. M. Worlock, Phys. Rev. 147, 636 (1966)

8. D. Walton, Phys. Rev. 157,720 (1967)

9. D. Walton and Lee, Phys Rev 157. 724 (1967)

10. E. Miescher, Nachr. Akad. Wiss. Gottingen, Math.-physik. Kl. 34,329 (1933)

11. A. B. Scott and W. A. Smith, Phys. Rev. 83, 982 (1951)

12. M. V. Klein, Phys. Rev. 122, 1393 (1961)

13. W. Gebhart, J. Phys. Chem. Solids 23, 1123 (1962)

14. R. 0. Pohl, Phys. Rev. Letters 8,481 (1962)

15. C. T. Walker and R. 0. Pohl, Phys. Rev. 131, 34 (1963)

16. J.: R. Clement, et al, Rev. Sci. Instr. 24, 545 (1963)

17. R. A. Guenther and H. Heinstock, Bull. Aro. Phys. Soc. 12, 671 (1967)

18. H. Weinstock, Phys. Letters 26A, 117 (1968)

19. H. Weinstock, Proceedings of Tenth International Conference on Low Temperature Physics (in press) 
20. D. I. Huber, Phys. Letters 25A, 93 (1967)

21. G. A. Slack, Phys. Rev. 122, 145i (1961)

22. H. Weinstock, BuIl. Am. Phys, Soc 11, 195 (1966)

\section{Reporting of Research}

3. "Thermal Conductivity of $\gamma$-Irradiated KCl below $I^{\circ} K^{\prime \prime}$ R. A. Guenther and H: Weinstock, Bull. Am. Phys. Soc. 12, 671 (1967)

2. "Possible Evidence of an Anomalous Enhancement in Thermal Conductivity due to Magnon Conductivity"; H. Weinstock, Phys. Letters 26A, 117 (1968)

\%. "Production and Measurement of Very Low Temperatures"; H. Heinstock, Cryogenic Techrology (in press)

$\because$ "Cryogenic Thermometry"; $H$. Weinstock in Introduction to Cryogenic Technology, edited by H. Weinstock, Boston Technical Publishers, Inc: (in press)

5. "Secondary Thermometry with Carbon Composition Resistors"; H. Weinstock and R. A. Guenther, being prepared for submission to Cryogenic Technology

6. "Evidence of Colloids in the Low Temperature Thermal Conductivity of Irradiated Alkali Halides"; R. A. Guenther and"H. Weinstock, being prepared for presentation at April, 1968 Meeting of the American Physical Society

7. "On Cryogenic Vacuum Seals with Indium"; R. A. Guenther and H. Weinstock, being prepared for submission to Notes section of Rev. Sci. Instr.

8. "Thermodynamic and Statistical Aspects of Magnetic Cooling"; H. Weinstock, published in January, 1968 issue of Am. J. Phys (involves work related to that being carried out in this research program) 
Theses In Preparation

3. "Thermal Conductivity of $\gamma$-Irradiated $\mathrm{KCl}$ Belon $I^{\circ} \mathrm{K} ", \mathrm{Ph} . \mathrm{D}$. Thesis, R. A. Guenther (expected June, 1968)

2. "Cryogenic Thermometry - Methods and Instrumentation", M.S. Thesis, R. F. Koch (expected June, 1968) 